GU J Sci, Part C, 6(3): 481-491 (2018)

Gazi Üniversitesi
Fen Bilimleri Dergisi
PART C: TASARIM VE TEKNOLOJI
dergipark.gov.tr/http-gujsc-gazi-edu-tr

\title{
Yüksek Emniyetli Mekanik Sistemlerin Yanıt Yüzey Destekli Kuyruk Modelleme Yöntemiyle Güvenilirlik Tahmini
}

\author{
Erdem $\mathrm{ACAR}^{1, *}$ \\ ${ }^{I}$ TOBB Ekonomi ve Teknoloji Üniversitesi, Mühendislik Fakültesi, Makine Mühendisliği Bölümü, 06560, Söğ̈̈tözü/ANKARA
}

\begin{abstract}
$\underline{\text { Öz }}$
Makale Bilgisi

Bașvuru: 22/06/2017

Düzeltme: 05/04/2018

Kabul: $29 / 05 / 2018$

Anahtar Kelimeler

Güvenilirlik tahmini

Mekanik sistemler

Kuyruk modeli

Yanıt yüzey yöntemi

Kuyruk modelleme yöntemi yüksek emniyetli mekanik sistemlerin güvenilirlik tahmininde kullanılan popüler bir yöntemdir. Klasik kuyruk modelleme yönteminde, kuyruk modeli oluşturulurken sadece dağılımın kuyruk bölgesine denk gelen sınır durum fonksiyonu verileri kullanılırken, arta kalan sınır durum fonksiyonu verileri ise boşa gider. Bu çalışmada, boşa giden veri miktarının azaltılması amacıyla, sınır durum fonksiyonu hesaplamalarının yanıt yüzey (YY) modeli kullanılarak kuyruk bölgesine yönlendirilmesi esasına dayanan yanıt yüzey destekli kuyruk modelleme (YYDKM) yöntemi önerilmiştir. YYDKM yönteminin hesap maliyetinin iki bileşeni bulunmaktadır: YY modeli oluşturmakla ilgili hesap maliyeti ve kuyruk modellemesiyle ilgili hesap maliyeti. YYDKM yönteminin doğruluğunun artırılması için hesap bütçesinin iki bileşen arasında uygun bir şekilde tahsis edilmesi gerekmektedir. Bu çalışmada, iki adet yapısal mekanik örnek problemi üzerinde hesap bütçesinin iki bileşen arasında tahsisi incelenmiştir. YY oluşturmak için tahsis edilen sınır durum fonksiyonu hesabı sayısının YY modelindeki katsayı adetinin 1.5 ile 2 katı arasında olmasının ve bu maliyetten arta kalan hesap bütçesinin kuyruk modellemesi için tahsis edilmesinin uygun olduğu görülmüştür.
\end{abstract}

Keywords

Reliability prediction

Mechanical systems

Tail modeling

Response surface method

\section{Reliability Prediction Of Highly Safe Mechanical Systems Using Response Surface Assisted Tail Modeling}

\begin{abstract}
Tail modeling method is a popular method for predicting reliability of highly safe mechanical systems. In classical tail modeling, only the limit-state values that belong to the tail part are used in tail model fitting, so majority of limit-state evaluations are wasted. This paper proposes response surface (RS) assisted tail modeling (RSATM) technique, where the limit-state evaluations are steered towards the tail part by using RS to reduce the amount of wasted data. The overall computational cost of RSATM is composed of two components: the cost related to RS model construction, and the cost related to tail modeling. To increase the accuracy of the RSATM, the computational budget should be allocated in a proper way. Two structural mechanics example problems are used to investigate the computational budget allocation in RSATM. It is found that the number of limit-state function evaluations allocated for RS construction can be limited between 1.5 and 2 times the number of coefficients in the RS model, and the rest of the computational budget can be allocated to tail modeling.
\end{abstract}

\section{GİRIŞ (INTRODUCTION)}

Mekanik sistemlerin güvenilirlik tahmini için, öncelikle rastgele değişkenler uzayını güvenli ve güvensiz bölge olarak ikiye ayıran çok boyutlu bir sınır durum fonksiyonu tanımlanır (geleneksel kullanımda, sınır durum fonksiyonunun negatif değerleri emniyetsizlik durumunu gösterirken, pozitif değerleri ise emniyetli durumu gösterir). Ardından, güvenli bölge dâhilinde, tüm rastgele değişkenlerin ortak olasılık yoğunluk fonksiyonunun çok boyutlu integrali hesaplanır ve elde edilen değer mekanik sistemin güvenilirliğini verir. Mekanik sistemlerin güvenilirlik tahmini için kullanılan yöntemler kabaca analitik yöntemler ve benzetim tabanlı yöntemler olmak üzere iki kategoriye ayrılabilir. 
Analitik yöntemler içerisinde en popüler olanları, sınır durum fonksiyonunun Taylor serisi açılımına dayanan birinci derece [1] ve ikinci derece [2-3] güvenilirlik yöntemleridir. Diğer analitik yöntemlere örnek olarak gelişkin ortalama değer yöntemi [4], Neumann açılımı yöntemi [5], nokta tahmin yöntemleri $[6,7]$ ve hızlı Fourier dönüşümü yöntemleri $[8,9]$ verilebilir. Analitik yöntemler hesap maliyeti (güvenilirlik tahmini için harcanan zaman) açısından avantajlı olmalarına rağmen, analitik çözüm için kullanılan varsayımlardan dolayı sınır durum fonksiyonu doğrusal olmayan ve yüksek emniyetli mekanik sistemlerin güvenilirlik tahmininde yüksek hatalar verebilirler [10].

Benzetim tabanlı yöntemler [11-15] analitik varsayım içermez, ancak yüksek emniyetli mekanik sistemlerin güvenilirliklerini bu yöntemleri kullanarak yüksek doğrulukla tahmin etmek gerektiğinde çok sayıda benzetim yapılması gerekir, dolayısıyla hesap maliyeti oldukça yüksektir. Hesap maliyetini azaltmak için kullanılan yöntemlerden birisi kuyruk modelleme yöntemidir ve birçok araştırmacı tarafindan kullanılmıştır [16-23].

Klasik kuyruk yöntemi şu prosedüre göre işler [19]: (i) uygun bir örnekleme yöntemi ile makul sayıda sınır durum fonksiyonu hesaplanır ve ampirik birikimli dağılım fonksiyonu elde edilir, (ii) dağılımın kuyruk kısmını tanımlayan uygun bir eşik değer seçilir (örneğin 0.90 veya 0.95 ), (iii) dağılımın kuyruk kısmı genelleştirilmiş Pareto dağılımı ile ifade edilir ve elde edilen dağılım ile güvenilirlik tahmini yapılır. Bu prosedüre göre; sadece kuyruk kısmındaki veriler kullanılırken, kuyruk kısmı haricindeki veriler (tüm verilerin \%90 veya \%95'i) boşa gider. Eğer boşa giden veri miktarı azaltılabilirse, bu yöntemin doğruluğu artırılabilir.

Boşa giden veri miktarını azaltmak için çeşitli yöntemler önerilmiştir. Ramu ve Krishna [24] dışbükey örtü stratejisini kullanarak önce makul sayıda sınır durum fonksiyonu hesabı yaparak bir dışbükey örtü oluşturmuş ve bu örtüyü sınır durum fonksiyonu hesabını kuyruk bölgesine yönlendirmek için kullanmıştır. Oluşturulan her bir yeni sınır durum değeri kullanılarak dışbükey örtü güncellenmiş ve güncel son dışbükey örtü güvenilirlik tahmininde kullanılmıştır. Bu yöntemin en zayıf tarafı, problemdeki rassal değişken sayısı arttıkça yönteminin doğruluğunun azalmasıdır. Acar [25] tarafindan önerilen Güdümlü Kuyruk Modelleme (GKM) yönteminde ise, sınır durum fonksiyonu hesabının kuyruk bölgesine yönlendirilmesi için, tek değişkenli boyut indirgeme yöntemi [26] ve genişletilmiş genelleştirilmiş lambda dağılımının [27] birlikte kullanımına dayanan bir yaklaşım geliştirilmiştir. GKM yönteminin temel eksikliğii, problemdeki rassal değişken sayısı arttıkça ve rassal değişkenler arasında korelasyon olduğunda doğruluğunun azalmasıdır.

$\mathrm{Bu}$ çalışmada, rassal değişken sayısı görece yüksek ve rassal değişkenler arasında korelasyon bulunan problemler için kullanılabilecek yeni bir güvenilirlik tahmin yöntemi geliştirilerek literatüre katkıda bulunmak hedeflenmektedir. Önerilen yöntem, sınır durum fonksiyonu hesaplamalarının yanıt yüzey modeli kullanılarak kuyruk bölgesine yönlendirilmesi esasına dayanmaktadır.

Makalenin geri kalan kısmı şu şekilde organize edilmiştir: Bölüm 2'de literatürde mevcut kuyruk modelleme yöntemleri anlatılmış ve bu makalede önerilen yöntem açıklanmıştır. Bölüm 3 'te bu çalışmada kullanılan örnek problemler tanımlanmıştır. Bölüm 4'te elde edilen bulgular sunulmuş ve tartışılmıştır. Bölüm 5'te bu çalışmadan elde edilen sonuçlar sunulmuştur.

\section{YÖNTEMLER (METHODS)}

\subsection{Mevcut Yöntemler (Existing Methods)}

\section{Klasik Kuyruk Modelleme Yöntemi}

İlgilenilen mekanik sistemin sınır durum fonksiyonu $\mathbf{y}(\mathbf{X})$, rassal değişken vektörü $\mathbf{X}$ 'in fonksiyonu olarak tanımlanabilir. Şekil 1'de gösterilen olasılık dağılımının belirli bir eşik değerinin $\left(F_{t}\right)$ üstünde tanımlanan kuyruk kısmı, Genelleştirilmiş Pareto Dağılımı (GPD) ile modellenebilir. GPD, Denklem 1 ile formüle edilen koşullu fazlalık dağılımı $F_{z}(z)$ 'nin modellenmesinde kullanılır, burada $z=y-y_{t}$ olarak tanımlanır. 


$$
F_{z}(z)=\left\{\begin{array}{l}
1-\left\langle 1+\frac{\xi}{\sigma} z\right\rangle_{+}^{-\frac{1}{\xi}} \text { if } \xi \neq 0 \\
1-\exp \left(-\frac{z}{\sigma}\right) \text { if } \xi=0
\end{array}\right.
$$

Denklem 1'de $\langle A\rangle_{+}=\max (0, A), z \geq 0$ ve $F_{z}(z)$ ise şekil ve ölçek parametreleri sırasılyla $\xi$ ve $\sigma$ ile gösterilen GPD'dir.

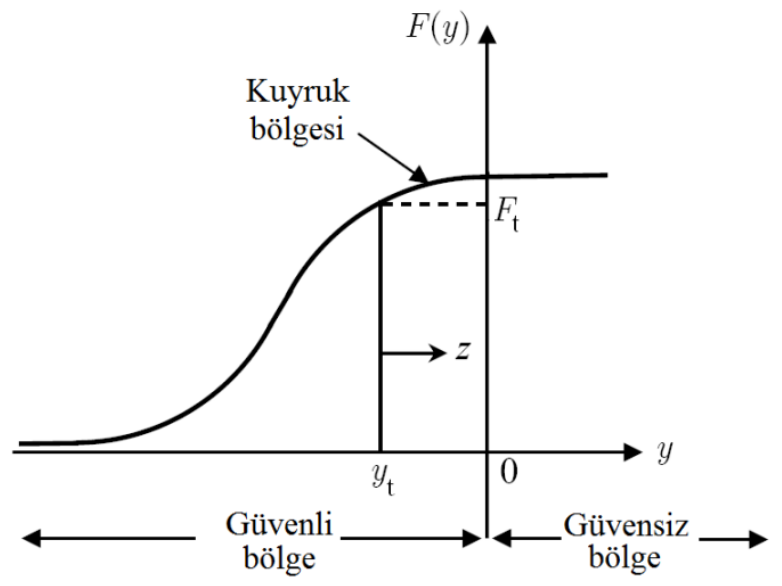

Şekil 1. Kuyruk modelleme konsepti (Tail modeling concept)

Eşik değerin üstündeki birikimli dağılım $F(y)$, koşullu fazlalık olasılık dağılımı ve eşik değeri $F_{t}$ cinsinden Denklem 2'de verildiği üzere elde edilebilir.

$$
F(y)=F_{t}+\left(1-F_{t}\right) F_{z}\left(y-y_{t}\right)
$$

Son olarak, güvenilirlik ( $R e l)$ tahmini Denklem 3 kullanılarak yapılabilir

$$
R e l=F(y=0)=F_{t}+\left(1-F_{t}\right)\left\langle 1-\frac{\xi}{\sigma} y_{t}\right\rangle_{+}^{-\frac{1}{\xi}}
$$

Hesaplanan güvenilirlik değeri, güvenilirlik indisi değerine Denklem 4 kullanılarak dönüştürülebilir. Denklemde $\Phi$ standart normal dağılımın olasılık dağılım fonksiyonudur.

$$
\beta=\Phi^{-1}(\operatorname{Rel})
$$

Not edilmelidir ki, kuyruk modellemesi yönteminde sınır durum fonksiyonu olasılık dağılımının üst kuyruk kısmı modellendiği için, sınır durum fonksiyonunun pozitif değerleri emniyetsizlik durumunu göstermektedir. $\mathrm{Bu}$ durum, sınır durum fonksiyonunun negatif değerlerinin emniyetsizlik durumunu gösterdiği geleneksel kullanıma zıttır.

Klasik kuyruk modelleme yöntemi aşağıdaki prosedüre dayanır [19]:

1. Monte Carlo simülasyonu veya Latin hiperküp örnekleme yöntemi ile $N$ adet rassal girdi değişkenleri kombinasyonu oluşturulur ve bu kombinasyonlar için sınır durum fonksiyonu hesaplanır. Bu çalışmada hesap bütçesi (hesap kaynakları gereği yapılabilecek en fazla sınır durum fonksiyonu hesabı sayısı) $N=500$ olarak belirlenmiştir.

2. Sınır durum fonksiyonunun ampirik birikimli olasılık dağılımı elde edilir ve kuyruk bölgesini tanımlayacak bir eşik değeri $\left(F_{t}\right)$ belirlenir. Literatürde, uygun eşik değerin belirlenmesi üzerine çalışmalar mevcuttur $[28,29]$. Bu çalışmada eşik değer olarak $F_{t}=0.90$ kullanılmıştır. 
3. Eşik değerin üzerindeki $N_{t}=\left(1-F_{t}\right) N$ adet örnekleme noktası kullanılarak GPD'nin şekil ve ölçek parametreleri belirlenir. Bu amaçla kullanılan en popüler yöntem maksimum olabilirlik yöntemidir [19] ve bu çalışmada da maksimum olabilirlik yöntemi kullanılmıştır.

\section{Güdümlü Kuyruk Modelleme Yöntemi}

Daha önce de belirtildiği üzere, klasik kuyruk modellemesi yönteminde, yapılan $N$ adet sınır durum fonksiyonu hesabının sadece $N_{t}$ kadarı kullanılmakta, geri kalan kısmı ise kullanılmamaktadır. Eğer elde sınır durum fonksiyonu için yaklaşık bir model olsa ve $F_{t}$ eşik değerine karşılık gelen sınır durum fonksiyonu değeri $\left(y_{t}\right)$ bilinse, sınır durum fonksiyonu hesaplamaları kuyruk bölgesinde sonuç verme ihtimali yüksek olan örnekleme noktalarına doğru yönlendirilebilir. Acar [25] tarafından önerilen GKM yönteminde, sınır durum fonksiyonu hesabının kuyruk bölgesine yönlendirilmesi için, tek değişkenli boyut indirgeme (TDBİ) yöntemi ve genişletilmiş genelleştirilmiş lambda dağılımının (GGLD) birlikte kullanımına dayanan bir yaklaşım izlenmiştir.

TDBİ yöntemi, çok değişkenli bir fonksiyonun birden fazla tek değişkenli fonksiyon cinsinden tahminine dayanmaktadır. $N$ değiş̧enli bir $\mathrm{y}(\mathbf{X})$ fonksiyonu, tek değişkenli $y_{j}^{u}\left(X_{j}\right)$ fonksiyonları cinsinden Denklem 5'te verildiği gibi ifade edilebilir:

$$
\hat{y}(\mathbf{X})=\sum_{j=1}^{N} y_{j}^{u}\left(X_{j}\right)-(N-1) y_{0}
$$

Burada, toplama simgesinin içindeki $y_{j}^{u}$ terimi sadece $X_{j}$ rassal değişkenine bağli tek değişkenli bir fonksiyon olup, $y_{0}$ ise rassal değişkenlerin ortalama değerlerini aldıkları durumda $y(\mathbf{X})$ fonksiyonunun değeridir. TDBİ yöntemi, aynı zamanda sınır durum fonksiyonunun istatistiksel momentlerinin hesabında da kullanılır. Sayfa sınırlamasından dolayı gerek $y_{j}^{u}$ ve $y_{0}$ terimlerinin hesabında gerekse istatistiksel moment hesabında kullanılan formüller bu makalede verilmemiş olup, gerekli bilgiler Acar [25]'ın çalışmasında bulunabilir.

Sinır durum fonksiyonu istatistiksel momentleri hesaplandıktan sonra, bu momentler GGLD'nin istatistiksel momentleriyle eşitlenerek GGLD parametreleri hesaplanır. Ardından, sınır durum fonksiyonu eşik değeri Denklem 6 ile kolayca hesaplanır. Denklemde $F_{G G L D}$ fonksiyonu GGLD'nin birikimli olasılık dağılım fonksiyonudur.

$$
y_{t}=F_{G G L D}^{-1}\left(F_{t}\right)
$$

GKM yönteminin doğruluk ve etkinliği ilgilenilen problemin doğrusallık derecesinden, problemdeki rassal değişkenlerin olasılık dağılım tiplerinden fazla etkilenmemektedir. Ancak, problemdeki rassal değişken sayısı arttıkça ve rassal değişkenler arasında korelasyon olduğunda, çok değişkenli bir fonksiyonu tek değişkenli fonksiyonların doğrusal bir fonksiyonu olarak ifade eden TDBİ yöntemi yüksek hatalar vermektedir [30]. Dolayısıyla, TDBİ yöntemi kullanımına dayanan GKM yöntemi de yüksek hatalar vermektedir. Dolayısıyla, bu çalışmada önerilen yöntem ile GKM yönteminin doğrulukları için karşılaştırma yapılmamıştır.

\section{2. Önerilen Yöntem (Proposed Method)}

Bu çalışmada, rassal değişken sayısı görece yüksek ve rassal değişkenler arasında korelasyon bulunan problemler için kullanılabilecek yeni bir güvenilirlik tahmin yöntemi geliştirmiştir. Önerilen yöntem, sınır durum fonksiyonu hesaplamalarının yanıt yüzey (YY) modeli kullanılarak kuyruk bölgesine yönlendirilmesi esasına dayanmaktadır ve yanıt yüzey destekli kuyruk modelleme (YYDKM) yöntemi olarak adlandırılmıştır.

En sık kullanılan YY modeli, formülasyonu Denklem 7'de verilen ikinci derece polinom formunda YY modelidir ve bu çalışmada da kullanılmıştır. 


$$
\hat{y}(\mathbf{x})=b_{0}+\sum_{i=1}^{N_{v}} b_{i} x_{i}+\sum_{i=1}^{N_{v}} b_{i i} x_{i}^{2}+\sum_{i=1}^{N_{v}-1} \sum_{j=i+1}^{N_{v}} b_{i j} x_{i} x_{j}
$$

Burada $\hat{y}(\mathbf{x})$ asıl yanıt olan $y(\mathbf{x})$ 'nin tahmini için oluşturulan YY modeli, $N_{v}$ terimi ise $\mathbf{x}$ girdi vektöründeki değişken sayısıdır. YY modelindeki $b_{0}, b_{i}, b_{i i}$ ve $b_{i j}$ katsayıları en küçük kareler yöntemiyle hesaplanabilir.

Önerilen yöntemin hesap maliyetinin iki bileşeni bulunmaktadır: YY modeli oluşturmakla ilgili hesap maliyet ve kuyruk modellemesiyle ilgili hesap maliyeti. Hesap bütçesinin bu iki bileșen arasında uygun bir şekilde tahsis edilmesiyle önerilen yönteminin doğruluğu artırılabilir. Önerilen yöntem için takip edilecek prosedür Tablo 1'de sunulmuştur.

Tablo 1. Önerilen yöntem için prosedür (Procedure for the proposed method)

1. YY modeli oluşturmak için kullanılacak sınır durum fonksiyonu hesabı sayısını $\left(N_{Y Y}\right)$ belirle.

2. Her bir rassal değişken için ortalamanın üç standart sapma altında ve üstünde olacak şekilde alt ve üst sınırları belirle. Alt ve üst sınırlar dâhilinde uygun bir örnekleme yöntemiyle $\mathrm{N}_{\mathrm{YY}}$ adet veri noktası oluştur ve bu noktalara karşılık gelen sınır durum fonksiyonu değerlerini hesapla.

3. Sınır durum fonksiyonu değerleri ile veri noktaları arasında YY modeli oluştur.

4. YY modelini kullanarak, sınır durum fonksiyonu eşik değerini $\left(y_{t}\right)$ hesapla.

5. Uygun bir örnekleme yöntemiyle $N_{p}$ adet (örneğin $N_{p}=10.000$ ) potansiyel örnekleme noktas1 oluştur. YY modelini kullanarak potansiyel örnekleme noktalarında sınır durum fonksiyonunun tahmini değerini hesapla ve $\mathrm{y}_{\mathrm{t}}$ 'den yüksek olanları depola.

6. Depolanan örnekleme noktaları arasından $N-N_{Y Y}$ adet rastgele nokta seç ve bu noktalar için sınır durum fonksiyonunun asıl değerlerini hesapla, GPD kuyruk modeli oluştur ve güvenilirlik tahmini yap.

\section{3. ÖRNEK PROBLEMLER (EXAMPLE PROBLEMS)}

\subsection{Fortini'nin kavrama problemi (Fortini’s clutch problem)}

Lee ve Kwak'ın çalışmasından [31] alınan ve Şekil 2'de gösterilen serbest tekerlek kavraması, Fortini'nin kavrama problemi olarak bilinir. Fortini'nin kavrama probleminde $x_{1}, x_{2}, x_{3}$ ve $x_{4}$ olmak üzere dört adet rassal değişken bulunmaktadır ve bu rassal değişkenler kavrama üzerinde Şekil 2'de belirtilen uzunlukları temsil etmektedir.

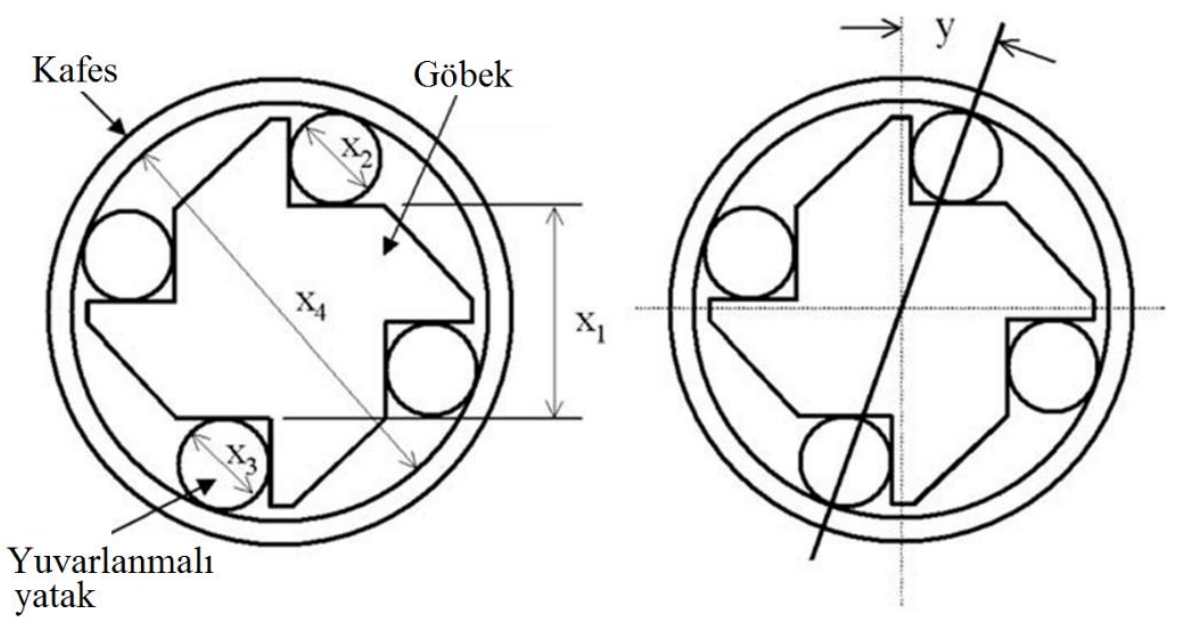

Şekil 2. Fortini'nin kavramast (Fortini's clutch) 
Bu problemde temas açısı (y), rassal değişkenler cinsinden Denklem 8 kullanılarak hesaplanabilir:

$$
y\left(x_{1}, x_{2}, x_{3}, x_{4}\right)=\arccos \left[\frac{x_{1}+0.5\left(x_{2}+x_{3}\right)}{x_{4}-0.5\left(x_{2}+x_{3}\right)}\right]
$$

Bu problem için aşağıda verilen sınır durum fonksiyonu kullanılabilir:

$$
Y=y_{\text {crit }}-y\left(x_{1}, x_{2}, x_{3}, x_{4}\right)
$$

Denklem 9'daki $y_{\text {crit }}$ değeri temas açısı için tanımlanan kritik değeri göstermektedir ve temas açısının bu değerden küçük olması (yani Y'nin pozitif olması) emniyetsiz durumu göstermektedir. Bu çalışmada $y_{\text {crit }}$ değeri $5^{\circ}$ olarak alınmıştır. Problemdeki tüm rassal değişkenler normal dağılıma sahiptir, bu değişkenlerin ortalama ve standart sapma değerleri Tablo 2'de verilmiştir. Rassal değişkenler arasındaki korelasyon katsayısı için iki farklı korelasyon katsayısı değeri (0.25 ve 0.5) kullanılmıştır. Sınır durum fonksiyonu $Y=y_{\text {crit }}-y(\mathbf{x})$ biçiminde olduğundan, korelasyon katsayısı arttıkça güvenilirlik artmaktadır.

Tablo 2. Fortini'nin kavrama problemindeki rassal değişkenlerin ortalama ve standart sapma değerleri (Mean and standard deviation values of the random variables in Fortini's clutch problem)

\begin{tabular}{|c|c|c|}
\hline Rassal değişken & Ortalama & Standart sapma \\
\hline$x_{1}$ & 55.29 & 0.0793 \\
\hline$x_{2}$ & 22.86 & 0.0043 \\
\hline$x_{3}$ & 22.86 & 0.0043 \\
\hline$x_{4}$ & 101.60 & 0.0793 \\
\hline
\end{tabular}

\subsection{On çubuklu kafes problemi (Ten-bar truss problem)}

Şekil 3'te gösterilen on çubuklu kafes yapısında, 2 ve 3 numaralı düğüm noktaları $P_{1}=P_{2}=444.8 \mathrm{kN}$ $\left(\mathrm{P}_{1}=\mathrm{P}_{2}=100\right.$ kips) kuvvetlerine maruz kalmaktadır. Kafes malzemesi alüminyum olup; özkütlesi $\rho=2768$ $\mathrm{kg} / \mathrm{m}^{3}\left(\rho=0.1 \mathrm{lb} / \mathrm{in}^{3}\right)$, elastisite modülü $E=70 \mathrm{GPa}\left(E=10^{4} \mathrm{ksi}\right)$ değerlerine sahiptir. Şekildeki geometri parametresi $b$ 'nin değeri $9.144 \mathrm{~m}$ (360 in) olarak alınmıştır.

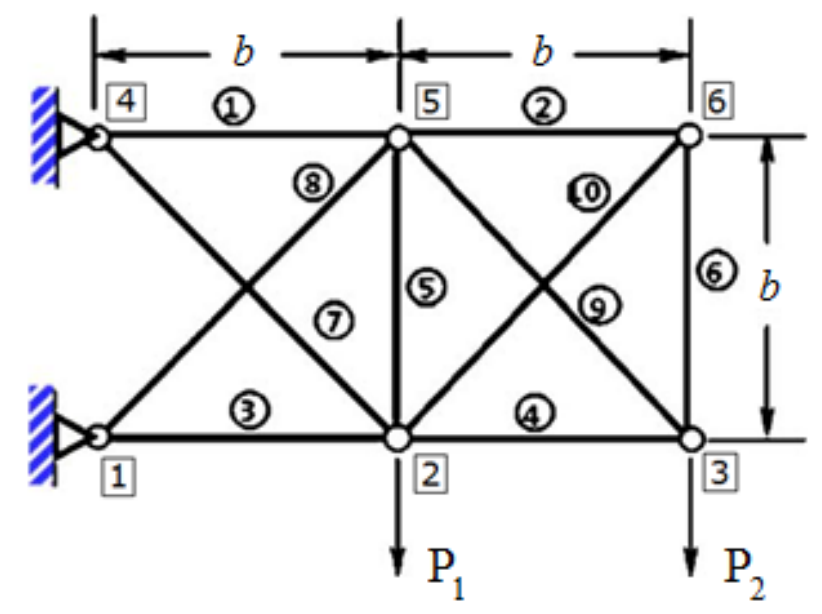

Şekil 3. On çubuklu kafes üzerindeki yükleme ve sınır koşulları (Loading and boundary conditions for the ten-bar truss problem)

Bu kafes sisteminin tasarımı, 3 no.lu düğüm noktasındaki yer değiştirmenin belirli bir kritik değerin altında kalması şartına göre yapılmaktadır. Bu problem için sınır durum fonksiyonu şu şekilde yazılabilir:

$$
Y=v_{3}(\mathbf{A})-v_{c r i t}
$$

Burada A kafes sistemindeki çubukların kesit alanlarının oluşturduğu $10 \times 1$ boyutlarındaki vektördür. Denklem 10'daki $v_{\text {crit }}$ değeri 3 no.lu düğüm noktasındaki yer değiştirme için tanımlanan kritik değeri göstermektedir ve yerdeğiştirmenin bu değerden yüksek olması (yani Y'nin pozitif olması) emniyetsiz durumu göstermektedir. Bu çalışmada $v_{\text {crit }}=76.2 \mathrm{~cm}(30$ in) olarak alınmıştır. 3 no.lu düğüm 
noktasındaki yer değiştirmeyi hesaplamak için, öncelikle çubuklardaki iç kuvvetler hesaplanır [32]. İç kuvvetler hesaplandıktan sonra, enerji yöntemleri (örneğin, virtuel kuvvet yöntemi) kullanılarak 3 no.lu dügüm noktasındaki yer değiştirme kolayca hesaplanabilir.

$\mathrm{Bu}$ problemde yükleme ve malzeme özellikleri deterministik değerler olarak alınırken, çubuk kesit alanları rassal değişkenler olarak alınmıştır. Tüm kesit alanları normal olasılık dağılımına sahip olup; ortalamas $16.13 \mathrm{~cm}^{2}\left(2.5 \mathrm{in}^{2}\right)$, standart sapması $3.226 \mathrm{~cm}^{2}\left(0.5 \mathrm{in}^{2}\right)$ olarak alınmıştır. Rassal kesit alanları arasında korelasyon katsayısı için iki farklı korelasyon katsayısı değeri (0.25 ve 0.5) kullanılmıştır. Sınır durum fonksiyonu $Y=y(\mathbf{x})-y_{\text {crit }}$ biçiminde olduğundan, korelasyon katsayısı arttıkça güvenilirlik azalmaktadır.

\section{BULGULAR (RESULTS)}

$\mathrm{Bu}$ çalışmada önerilen güvenilirlik tahmin yönteminin doğruluğu Bölüm 3'te detayları verilen örnek problemler için hesaplanmıştır. Önerilen yöntem benzetim tabanlı bir yöntem olduğundan, rastgele örneklemenin etkisini azaltmak için tüm prosedür $1000 \mathrm{kez}$ tekrarlanmış ve Denklem 11 kullanılarak ortalama mutlak hata $(\mathrm{OMH})$ hesabı yapılmıştır:

$$
O M H=\frac{1}{n} \sum_{i=1}^{n}\left|\frac{\beta_{\text {pred }}}{\beta_{\text {act }}}-1\right| \times 100
$$

Burada $n$ rastgele örneklemenin etkisini azaltmak için yapılan tekrar sayısı $(n=1000), \beta_{\text {pred }}$ güvenilirlik indisinin tahmini değeri, $\beta_{\text {act }}$ ise güvenilirlik indisinin 100 milyon örneklemeli Monte Carlo simülasyonu ile hesaplanan ve güvenilirlik indisinin asıl değeri olarak kabul edilebilecek değeri ifade etmektedir.

Her iki örnek problem için de, OMH'nin $\mathrm{N}_{Y Y}$ 'ye göre değişimi ele alınmış ve en uygun $\mathrm{N}_{\mathrm{YY}}$ değeri belirlenmiştir. $\mathrm{N}_{Y Y}$ için seçilen aralık yaklaşık olarak YY modelindeki katsayı adetinin 1 ile 4 katı arası olacak şekilde belirlenmiştir.

\subsection{Fortini'nin kavrama problemi (Fortini’s clutch problem)}

Fortini'nin kavrama probleminde, rassal değişkenler arasındaki korelasyon katsayısı 0.25 olduğunda elde edilen bulgular Şekil 4(a)'da sunulmuştur. Ortak hatayı en küçükleyen $\mathrm{N}_{\mathrm{YY}}$ değeri 30 olarak bulunmuştur. Bununla birlikte, $\mathrm{N}_{\mathrm{YY}}=25$ ve $\mathrm{N}_{\mathrm{YY}}=35$ için elde edilen $\mathrm{OMH}$ değerleri $\mathrm{N}_{\mathrm{YY}}=30$ için elde edilen $\mathrm{OMH}$ değerine oldukça yakındır. Benzer şekilde, rassal değişkenler arasındaki korelasyon katsayısı 0.5 olduğunda elde edilen bulgular ise Şekil 4(b)'de verilmiştir. Ortak hatayı en küçükleyen $N_{Y Y}$ değeri 40 olarak bulunmuştur. Ayrıca, $\mathrm{N}_{\mathrm{YY}}=35$ ve $\mathrm{N}_{\mathrm{YY}}=45$ için elde edilen $\mathrm{OMH}$ değerlerinin $\mathrm{N}_{\mathrm{YY}}=40$ için elde edilen $\mathrm{OMH}$ değerlerine oldukça yakın olduğu görülmektedir.

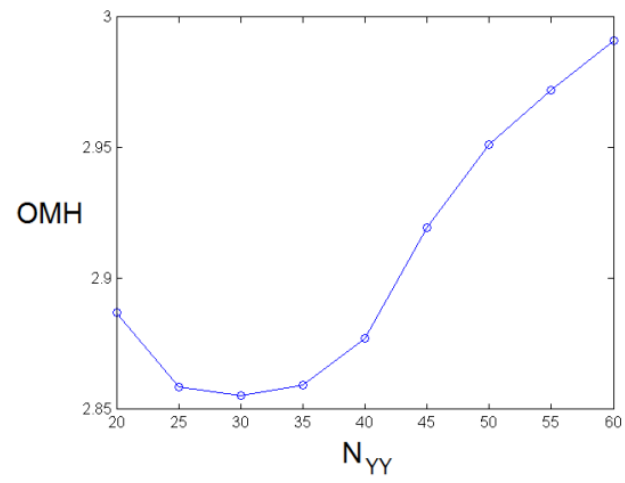

(a)

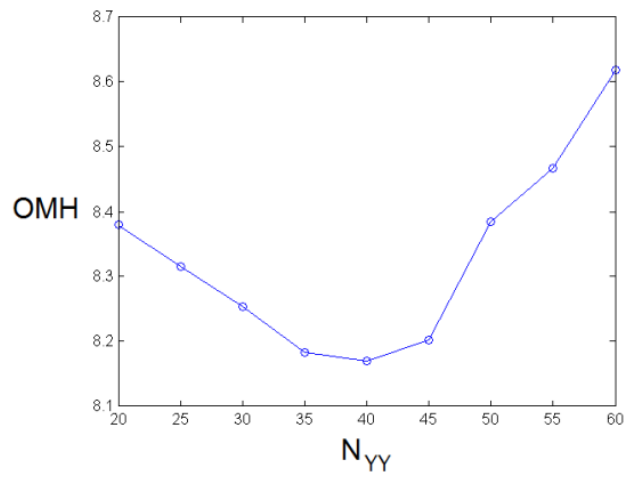

(b)

Şekil 4. Fortini'nin kavrama probleminde (a) 0.25 korelasyon katsayısı için, (b) 0.5 korelasyon katsayısı için, OMH'nin $N_{Y Y}$ 'ye göre değişimi (Change of OMH with respect to $N_{Y Y}$ in Fortini's clutch problem (a) for 0.25 correlation coefficient, (b) for 0.5 correlation coefficient) 
Fortini'nin kavrama problemi dört değişkenli bir problemdir. Dört değişkenli bir problem için oluşturulacak ikinci derece polinom formda YY modelinde toplam 15 katsayı bulunmaktadır. Şekil 4(a) ve 4(b)'de verilen bulgulara binaen, $\mathrm{N}_{\mathrm{YY}}$ değerinin $\mathrm{YY}$ modelindeki katsayı adetinin yaklaşık 1.5 ile 2.5 katı aralığında (25 ile 40 aralığında) olmasının uygun olduğu sonucuna ulaşılmaktadır.

YYDKM'da bu problem için en uygun $\mathrm{N}_{Y Y}$ kullanıldığında elde edilen doğruluğu ile klasik kuyruk modeli (KKM) yönteminin doğruluğunun karşılaştırması Tablo 3'te verilmiştir. Tablo 3'ün 2. ve 3. sütununda verilen değerler $n=1000$ tekrar ile elde edilen ortalama değerler, parantez içindeki değerler ise standart sapma değerleridir. YYDKM ve KKM sonuçları karşılaştırıldığında; YYDKM yöntemi ile elde edilen güvenilirlik tahminlerinin (ortalama değerlerinin) güvenilirlik indisinin asıl değerine daha yakın, standart sapmalarının ve $\mathrm{OMH}$ değerlerinin daha düşük olduğu görülmektedir.

Tablo 3. YYDKM ve KKM yöntemlerinin doğruluklarının Fortini'nin kavrama problemi için karşılaştırması (Comparison of the accuracies of YYDKM and KKM methods for Fortini's clutch problem)

\begin{tabular}{|c|c|c|c|c|c|}
\hline $\begin{array}{c}\text { Korelasyon } \\
\text { katsay1s1 }\end{array}$ & $\beta_{\text {act }}$ & $\begin{array}{c}\beta_{\text {pred }} \\
\text { KKM }\end{array}$ & $\begin{array}{c}\beta_{\text {pred }} \\
\text { YYDKM }\end{array}$ & $\begin{array}{c}\text { OMH } \\
\text { KKM }\end{array}$ & $\begin{array}{c}\text { OMH } \\
\text { YYDKM }\end{array}$ \\
\hline 0.25 & 2.99 & $3.15(0.53)$ & $2.99(0.11)$ & 11.7 & 2.9 \\
\hline 0.5 & 3.65 & $3.70(0.93)$ & $3.68(0.42)$ & 17.6 & 8.2 \\
\hline
\end{tabular}

\subsection{On çubuklu kafes problemi (Ten-bar truss problem)}

On çubuklu kafes probleminde, rassal değişkenler arasındaki korelasyon katsayısı 0.25 olduğunda elde edilen bulgular Şekil 5(a)'da sunulmuştur. Ortak hatayı en küçükleyen $\mathrm{N}_{\mathrm{YY}}$ değeri 100 olarak bulunmuştur. Bununla birlikte, $\mathrm{N}_{Y Y}=90$ ve $\mathrm{N}_{Y Y}=110$ için elde edilen $\mathrm{OMH}$ değerleri $\mathrm{N}_{\mathrm{YY}}=100$ için elde edilen $\mathrm{OMH}$ değerine oldukça yakındır.

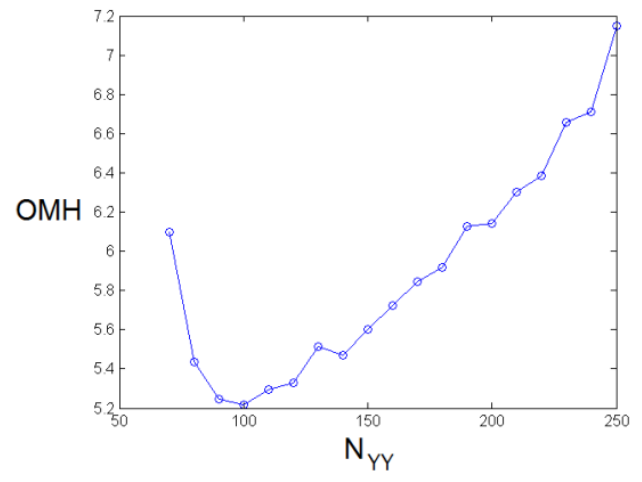

(a)

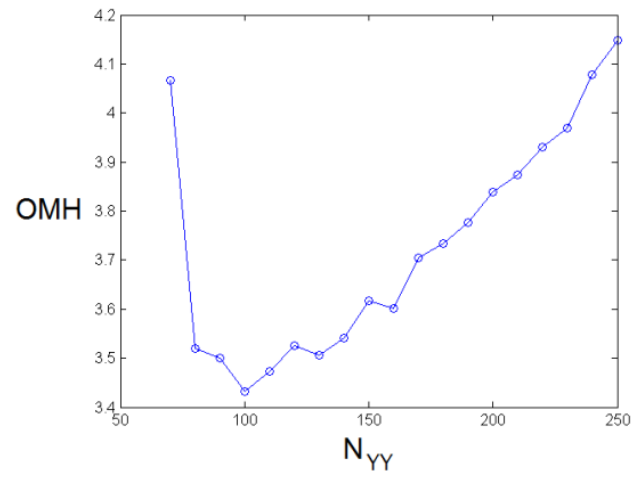

(b)

Şekil 5. On çubuklu kafes probleminde (a) 0.25 korelasyon katsayısı için, (b) 0.5 korelasyon katsayısı için, OMH'nin $N_{Y Y}$ 'ye göre değişimi (Change of OMH with respect to $N_{Y Y}$ in ten-bar truss problem (a) for 0.25 correlation coefficient, (b) for 0.5 correlation coefficient)

On çubuklu kafes probleminde, rassal değişkenler arasındaki korelasyon katsayısı 0.5 olduğunda elde edilen bulgular Şekil 5(b)'de verilmiştir. Ortak hatayı en küçükleyen $\mathrm{N}_{Y Y}$ değeri 100 olarak bulunmuştur. Bununla birlikte, $\mathrm{N}_{\mathrm{YY}}=90$ ve $\mathrm{N}_{\mathrm{YY}}=110$ için elde edilen $\mathrm{OMH}$ değerleri $\mathrm{N}_{\mathrm{YY}}=100$ için elde edilen $\mathrm{OMH}$ değerine oldukça yakındır.

On çubuklu kafes problemi on değişkenli bir problemdir. On değişkenli bir problem için oluşturulacak ikinci derece polinom formda YY modelinde toplam 66 katsayı bulunmaktadır. Şekil 5(a) ve 5(b)'de 
verilen bulgulara binaen, $\mathrm{N}_{\mathrm{YY}}$ değerinin $\mathrm{YY}$ modelindeki katsayı adetinin yaklaşık 1.5 ile 2 katı aralığında (90 ile 130 aralığında) olmasının uygun olduğu sonucuna ulaşılmaktadır.

YYDKM'da bu problem için en uygun $\mathrm{N}_{\mathrm{YY}}$ kullanıldığında elde edilen doğruluğu ile klasik kuyruk modeli (KKM) yönteminin doğruluğunun on çubuklu kafes problemi için karşılaştırması Tablo 4'te verilmiştir. YYDKM ve KKM sonuçları karşılaştırıldığında; YYDKM yöntemi ile elde edilen güvenilirlik tahminlerinin (ortalama değerlerinin) güvenilirlik indisinin asıl değerine daha yakın, standart sapmalarının ve $\mathrm{OMH}$ değerlerinin de daha düşük olduğu görülmektedir.

Tablo 4. KKM ve YYDKM yöntemlerinin doğruluklarının on çubuklu kafes problemi için karşılaştırması (Comparison of the accuracies of KKM and YYDKM methods for ten-bar truss problem)

\begin{tabular}{|c|c|c|c|c|c|}
\hline $\begin{array}{c}\text { Korelasyon } \\
\text { katsay1s1 }\end{array}$ & $\beta_{\text {act }}$ & $\begin{array}{c}\beta_{\text {pred }} \\
\text { KKM }\end{array}$ & $\begin{array}{c}\beta_{\text {pred }} \\
\text { YYDKM }\end{array}$ & $\begin{array}{c}\text { OMH } \\
\text { KKM }\end{array}$ & $\begin{array}{c}\text { OMH } \\
\text { YYDKM }\end{array}$ \\
\hline 0.25 & 3.35 & $3.60(0.81)$ & $3.39(0.25)$ & 16.1 & 5.2 \\
\hline 0.5 & 2.89 & $3.05(0.46)$ & $2.84(0.11)$ & 10.7 & 3.4 \\
\hline
\end{tabular}

\section{SONUÇ (CONCLUSION)}

Kuyruk modelleme yöntemi yüksek emniyetli mekanik sistemlerin güvenilirlik tahmininde kullanılan popüler bir yöntemdir. Bu çalışmada, kuyruk modelleme yönteminin doğruluğunu artırmak amacıyla, sınır durum fonksiyonu hesaplamalarının yanıt yüzey (YY) modeli kullanılarak kuyruk bölgesine yönlendirilmesi esasına dayanan yanıt yüzey destekli kuyruk modelleme (YYDKM) yöntemi önerilmiştir. YYDKM yönteminin hesap maliyetinin iki bileşeni bulunmaktadır: YY modeli oluşturmakla ilgili hesap maliyeti ve kuyruk modellemesiyle ilgili hesap maliyeti. YYDKM yönteminin doğruluğunun artırılmas1 için hesap bütçesinin iki bileşen arasında akıllıca tahsis edilmesi gerekmektedir. Bu çalışmada, iki adet yapısal mekanik örnek problemi üzerinde hesap bütçesinin iki bileşen arasında tahsisi incelenmiştir. YY oluşturmak için tahsis edilen sınır durum fonksiyonu hesabı sayısının YY modelindeki katsayı adetinin 1.5 ile 2 katı arasında olmasının ve arta kalan hesap bütçesinin kuyruk modellemesi için tahsis edilmesinin uygun olduğu görülmüsştür. Ayrıca, YYDKM yönteminin doğruluğunun KKM modelinin doğruluğundan oldukça yüksek olduğu görülmüştür.

\section{TEŞEKKÜR (ACKNOWLEDGMENTS)}

Bu çalışma TÜBİTAK tarafından 214M205 no.lu proje kapsamında desteklenmiştir.

\section{KAYNAKLAR (REFERENCES)}

[1] Hasofer, A.M., Lind, N.C., "Exact and Invariant Second-Moment Code Format," ASCE Journal of Engineering Mechanics Division, 100 (1974) 111-121.

[2] Fissler, B., Neumann, H.J., Rackwitz, R., "Quadratic Limit States in Structural Reliability,” ASCE Journal of the Engineering Mechanics Division, 105 (1979) 661-676.

[3] Hohenbichler, M., Gollwitzer, S., Kruse, W., Rackwitz, R., "New Light on First and Second-Order Reliability Methods," Structural Safety, 4: 4 (1987) 267-284.

[4] Wu, Y.T., Millwater, H.R., Cruse, T.A. "Advanced Probabilistic Structural Analysis Method for Implicit Performance Functions", AIAA Journal, 28: 9 (1990) 1663-1669.

[5] Yamazaki, F., Shinozuka, M., "Neumann expansion for stochastic finite element analysis," Journal of Engineering Mechanics, 114 (1988) 1335-1354. 
[6] Rosenblueth, E., "Point Estimates for Probability Moments," Applied Mathematical Modeling, 5 (1981) 329-335.

[7] Seo, H.S., Kwak, B.M., "Efficient Statistical Tolerance Analysis for General Distributions Using Three-Point Information,” International Journal of Production Research, 40: 4 (2002) 931-944.

[8] Sakamoto, J., Mori, Y., Sekioka, T., "Probability Analysis Method using Fast Fourier Transform and its Application", Structural Safety, 19: 1 (1997) 21-36.

[9] Adduri, P.R., Penmetsa, R.C., "Fast Fourier Transform Based System Reliability Analysis," International Journal of Reliability and Safety, 1: 3 (2007) 239-259.

[10] Acar, E., Rais-Rohani, M., Eamon, C.D., "Reliability Estimation Using Univariate Dimension Reduction and Extended Generalized Lambda Distribution, Handbook of Fitting Statistical Distributions with R, Editör: Karian Z.A., Dudewicz, E.J., CRC Press, 2010.

[11] Rubinstein, R.Y., Simulation and the Monte Carlo Method, Wiley, New York, NY, 1981.

[12] Melchers, R.E., "Importance Sampling in Structural Systems,” Structural Safety, 6 (1989) 3-10.

[13] Wu, Y.T., "Computational Methods for Efficient Structural Reliability and Reliability Sensitivity Analysis," AIAA Journal, 32: 8 (1994) 1717-1723.

[14] Nie, J., Ellingwood, B.R., "Directional Methods for Structural Reliability Analysis," Structural Safety, 22 (2000) 233-249.

[15] Au, S.K., Beck, J., "Estimation of small failure probabilities in high dimensions by subset simulation," Probabilistic Engineering Mechanics, 16 (2001) 263-277.

[16] Castillo, E., Extreme Value Theory in Engineering, Academic Press, San Diego, CA, 1988.

[17] Maes, M.A., Breitung, K., "Reliability-Based Tail Estimation," Proceedings of the IUTAM Symposium on Probabilistic Structural Mechanics (Advances in Structural Reliability Methods), San Antonio, TX, 335-346, 1993.

[18] Caers, J., Maes, M., "Identifying Tails, Bounds, and End-Points of Random Variables," Structural Safety, 20 (1998) 1-23.

[19] Kim, N.H., Ramu, P., Queipo, N.V., "Tail Modeling in Reliability-Based Design Optimization for Highly Safe Structural Systems," 47th AIAA/ASME/ASCE/ AHS/ASC Structures, Structural Dynamics, and Materials Conference, Newport, RI, Paper No: AIAA 2006-1825, 2006.

[20] Ramu, P., Kim, N.H., Haftka, R.T., "Multiple Tail Median Approach for High Reliability Estimation," Structural Safety, 32: 2 (2010) 124-137.

[21] Macdonald, A.E, "Extreme Value Mixture Modeling with Medical and Industrial Applications," PhD thesis, University of Canterbury, New Zealand, 2011.

[22] Lam, H., Mottet, C., "Simulating Tail Events with Unspecified Tail Models," Proceedings of the 2015 Winter Simulation Conference, Huntington Beach, CA, 392-402, 2015.

[23] Lim, W., Lee, T.H., Kang, S., Cho, S., "Estimation of Body and Tail Distribution Under Extreme Events for Reliability Analysis," Structural and Multidisciplinary Optimization, 54: 6 (2016) 16311639. 
[24] Ramu, P., Krishna, M., 2012, "A Variable-fidelity and Convex Hull Approach for Reliability Estimates in Tail Modeling," 14th AIAA/ISSMO Multidisciplinary Analysis and Optimization Conference, Indianapolis, IN, Paper No: AIAA 2012-5628, 2012.

[25] Acar, E., "Guided Tail Modeling for Efficient and Accurate Reliability Estimation of Highly Safe Mechanical Systems," Proceedings of the Institution of Mechanical Engineers, Part C: Journal of Mechanical Engineering Science, 225: 5 (2011) 1237-1251.

[26] Rahman, S., Xu, H., "A Univariate Dimension Reduction Method for Multi-dimensional Integration in Stochastic Mechanics," Probabilistic Engineering Mechanics, 19 (2004) 393-408.

[27] Karian, Z.E., Dudewicz, E.J., McDonald, P., "The Extended Generalized Lambda Distribution System for Fitting Distributions to Data: History, Completion of Theory, Tables, Applications, The "Final Word" on Moment Fits," Communications in Statistics - Computation and Simulation, 25: 3 (1996) 611-642.

[28] Boos, D., "Using extreme value theory to estimate large percentiles," Technometrics, 26: 1 (1984) 33-39.

[29] Hasofer, A., "Non-Parametric Estimation of Failure Probabilities," Mathematical Models for Structural Reliability, Editör: Casciati, F., Roberts, B., CRC Press, Boca Raton, FL, 195-226, 1996.

[30] Stocki, R., Lasota, R., Tauzowski, P., Szolc, T., "Scatter assessment of rotating system vibrations due to uncertain residual unbalances and bearing properties," Computer Assisted Methods in Engineering and Science, 19: 2 (2012) 95-120.

[31] Lee, T.W., Kwak, B.M., "A Reliability-Based Optimal Design Using Advanced First Order Second Moment Method," Mechanics of Structures and Machines, 15: 4 (1987) 523-542.

[32] Kumar S., Pippy, R.J., Acar, E., Kim, N.H, Haftka, R.T., “Approximate probabilistic optimization using exact-capacity-approximate-response-distribution (ECARD)," Structural and Multidisciplinary Optimization, 38 (2009) 613-626. 